\title{
Factors associated with returning to work after long term absence due to mental disorders
}

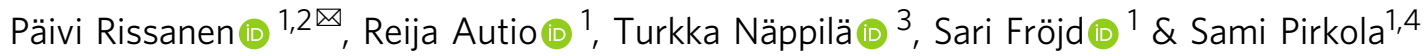

If there is a chance for a person's ability to work to be restored through treatment or rehabilitation, a temporary disability pension may be granted in Finland. We examined the personal, socio-economic and healthcare-related factors associated with return to work (RTW) after the receipt of temporary disability pension. The study material contains comprehensive register data of individuals who were granted a temporary disability pension due to a mental disorder (ICD10: F10-F69, F80-F99) for the first time between 2010 and 2012 $(N=8615)$. We applied clustering analysis in order to reveal different patterns of returning to work after receipt of temporary disability pension and utilized multinominal regression analysis to examine gender-specific determinants for RTW and partial RTW in a controlled setting. Being a lower-grade employee remarkably promoted RTW for women (OR 7.85 95\% $\mathrm{Cl}$ 5.35-11.51), as did being a manual worker for men (OR $5.4795 \% \mathrm{Cl} 3.48-8.78$ ). Moreover, both active male (OR $3.5195 \% \mathrm{Cl} 2.19-5.61$ ) and female manual workers (OR $2.4495 \% \mathrm{Cl}$ 1.66-3.59) had a higher probability of partial RTW compared to people who were initially unemployed. In addition, psychotherapy and vocational rehabilitation were associated with an increased probability of RTW. After 3 years from the initial temporary pensioning, almost two-thirds of the study population ( $69 \%$ of men and $64 \%$ of women) still had a temporary or by then a permanent disability pension due to a mental disorder. This and further research could improve the ability to recognize those subjects more likely to return to work than others.

\footnotetext{
${ }^{1}$ Faculty of Social Sciences, Tampere University, Tampere, Finland. ${ }^{2}$ The Finnish Central Association for Mental Health, Helsinki, Finland. ${ }^{3}$ Tampere University Library, Tampere University, Tampere, Finland. ${ }^{4}$ The Department of Adult Psychiatry of Tampere University Hospital, Tampere, Finland.

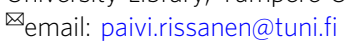




\section{Introduction}

ental disorders have become a key issue for social policy, healthcare, and the labour market in many OECD countries (OECD, 2013). Their prevalence is relatively high in the general population, and they are one of the major reasons for granting disability pensions (DP) (Pirkola et al., 2005). In addition, the cost to society in terms of health care, sick leave, and loss of productivity for employers is enormous (OECD, 2013). Hence, there is a strong political and economic incentive for encouraging people to continue working in accordance with their current capacity and to avoid a permanent premature exit from working life (Laaksonen and Gould, 2015). In Finland, the sickness and disability benefits systems are sequenced in an order of long-term sickness absence preceding DP (OECD, 2010), which then can be granted as a part-time, a temporary or a permanent. A DP can be granted to an individual aged 17-63 whose work ability has been reduced for more than one year. A temporary DP can be granted if there is a chance for the ability to work to be restored. This allows a re-evaluation of one's workability before being granted permanent DP and an early exit from working life (Pensioners and Insured in Finland, 2012, 2013).

It is now well established from a variety of studies that there are differences in socioeconomic status (SES) and personal factors, such as gender, in the presentation and prevalence of mental disorders as well as in disability pensioning and RTW. For example, the prevalences of substance use disorders and antisocial behaviours are higher in men, whereas depression and anxiety are more prevalent amongst women (Pirkola et al., 2005) The factors behind these differences are not only physical, genetic, or biological, but also social such as culture, family and gender roles, social status, and power. They may also contribute differences in the way they interact with each other (Hayashi et al., 2016; Murphy et al., 2019). In addition, several risk factors, such as the number of previous episodes and subclinical residual symptoms, for recurrence periods and chronicity of mental disorders have been identified (Hardeveld et al., 2010; Mattila-Holappa et al., 2017).

To date, several studies have investigated factors related to RTW after an absence from work due to mental (Blank et al., 2008; Cornelius et al., 2016; de Vries et al., 2018; MattilaHolappa et al., 2017). The factors related to the retirees' personal features and SES have been to some extent analysed. Firstly, several studies found evidence of a lower RTW rate for men (Blank et al., 2008; Cornelius et al., 2016; Ervasti et al., 2017; Laaksonen and Gould, 2015). By contrast, in a Japanese sample, men had a higher RTW rate than women (Hayashi et al., 2016). Secondly, younger age is associated with a higher RTW rate (Joensuu et al., 2018), and correspondingly an age of over 50 years with a lower rate (Cornelius et al., 2011; Ervasti et al., 2017). Thirdly, being married or cohabiting were related to a faster RTW (Huijs et al., 2017). Lastly, high SES, frequently measured by occupational status or education level, was associated with a greater likelihood of RTW in three Finnish studies (Ervasti et al., 2013; Mattila-Holappa et al., 2016; Virtanen et al., 2011). Interestingly, however, in one Dutch sample, higher education predicted a longer time before RTW (Nieuwenhuijsen et al., 2006). In addition, unemployment has been shown to be one of the risk factors for delayed RTW or no RTW (Laaksonen and Gould, 2015; MattilaHolappa et al., 2016).

Findings on the role of medical treatment, rehabilitation, psychotherapy and different work-oriented or multifaceted interventions promoting RTW have been heterogenous (Drake et al., 2013; Hees et al., 2012; Kuoppala and Lamminpää, 2008; Laaksonen and Gould, 2015; Suijkerbuijk et al., 2017). For example, some Finnish studies have suggested that cognitive behavioural therapy (Mattila-Holappa et al., 2016) and vocational rehabilitation during temporary DP (Laaksonen and Gould, 2015) may improve the RTW rate. On the other hand, some other studies have found no clear correlation between, for example, counselling, exercise, medical rehabilitation, or return-to-work programmes and RTW (Kuoppala and Lamminpää, 2008). In previous studies, the length of absence from work fluctuated. It was over 9 days in a Finnish sample (Ervasti et al., 2013), over 13 weeks in a Dutch sample (Blank et al., 2008; Cornelius et al., 2011; Laaksonen and Gould, 2015; Lagerveld et al., 2010; Mattila-Holappa et al., 2016), over 90 days in another Finnish sample (Virtanen et al., 2011) and over a year in four Finnish samples (Laaksonen and Gould, 2015; Mattila-Holappa et al., 2016; Pirkola et al., 2019). In some studies, the period of absence from work was unknown, as in a Japanese sample, where individuals had participated to the re-work day care program for patients who were absent from their work because of a psychiatric disorder (Hayashi et al., 2016). Then, in two Dutch studies, absence from work was associated with individuals' contract hours (Drake et al., 2013; Hees et al., 2012; Kuoppala and Lamminpää, 2008; Laaksonen and Gould, 2015; Suijkerbuijk et al., 2017) or it was measured by calculating the time to a full return to work during the follow-up period (Nieuwenhuijsen et al., 2006).

Numerous studies have investigated factors related to RTW after an absence from work for mental disorders, but there is a lack of studies of RTW after long-term (over one year) absence from work. Retirees' work ability may be restored totally or partially through recovery or treatment after being granted a DP. The aim of this study was to gain a better understanding of socio-economic factors associated with RTW and to examine the role of previous health care, such as received psychotherapy and rehabilitation, in RTW. For a more detailed investigation of possible paths to return to work, we performed a clustering analysis. We assumed there would be different types of predictors for different ways to recovery.

\section{Data and methods}

This study is part of the research project RETIRE, which aims to explore the sequences of and risk factors for psychiatric disability pensioning and to identify effective processes and models of the service system for preventing premature retirement and promoting RTW (Pirkola et al., 2019; Karolaakso et al., 2020, 2021).

Study population. The study population includes all individuals in Finland who were granted a temporary DP due to a mental disorder (ICD10: F10-F69, F80-F99) for the first time between 2010 and $2012(N=8615)$. We limited the population by excluding individuals who had received a permanent DP due to a mental disorder prior to 1 January 2010 or had received a temporary DP within one year before the index admission. The subjects were identified from the registers of The National Social Insurance Institution (SII) and the Finnish Centre for Pension (FCP), and each person was followed for 3 years after pensioning. Only those retirees who we could follow up for 3 years from the beginning of their temporary DP were included in the analysis.

Variables. The data were obtained from several nationwide registers: SII, FCP and personal and socio-economic data received from Statistics Finland. The subjects' ages were 
classified as $18-24,25-34,35-44,45-54$ and 55-63 years at the beginning of the pension. Family status was classified into four groups: (i) single, (ii) a couple, (iii) a couple with children, and (iv) single with children. Disposable income of a household was calculated based on OECD's consumption unit (Statistics Finland, 2019) using the information of individuals' incomes from registers of Statistic Finland and classified to quantiles as lowest (0-14,453 euros per year), middle-lower $(14,454-20,467)$, middle $(20,468-25,930)$, middle-higher $(25,931-33,253)$, and highest (over 33,254). Education level was measured by the duration of education in accordance with Statistics Finland's classification and was categorized as (i) basic (9 years of comprehensive education), (ii) upper secondary (intermediate), (iii) tertiary (universities of applied sciences, polytechnic) and (iv) higher degree (master, licentiate, and doctorate) levels. Occupational status was categorized based on Statistics Finland's classification (Statistics Finland, 1989) into seven categories as (i) upper-grade employees (upper-non-manual employees with administrative, managerial, professional and related occupations), (ii) lower-grade employees (lower-non-manual employees with administrative and clerical occupations), (iii) manual workers, (iv) students, (v) unemployed, (vi) self-employed, which included farmers on their own account, small employers, ownaccount workers and other self-employed persons and (vii) unknown.

The diagnoses for granting the DP were classified as F2*(F20-F29) Schizophrenia, schizotypal and delusional disorders, F3*(F30-F39) Mood [affective] disorders and other (F1*, $\left.\mathrm{F} 4 *-\mathrm{F} 6 *, \mathrm{~F} 8^{*}-\mathrm{F} 9 *\right)$. Regarding the service-related factors, data on previous psychotherapy and different forms of rehabilitation were recorded up to 5 years before being granted DP and classified as 'yes' or 'no'. Data were collected from the registers of the SII and the FCP.

Statistical analysis. Data of RTW were collected from the employment register of the insurance companies, which contains all employment contracts in Finland. The register is maintained by the Finnish Center for Pensions (FCP). For identifying the subjects with different types of patterns for RTW, we clustered the logarithmically transformed working days of the 3 years after retiring with the CLARA-clustering method with Euclidean distance. CLARA is an extension to partitioning around medoids (PAM) clustering and uses $k$ medoids for identifying the patterns in the data (Kaufman and Rousseeuw, 1990). We identified six clusters (clusters a-f) revealing the patterns by which the individual's returned to work, i.e., based on numbers of days at work during the 3 years follow-up (Fig. 1A). Then, we arranged the clusters in the three groups: RTW, partial RTW and no RTW (Fig. 1B). The RTW group was constituted in cluster a (individuals returned to work during the first year after pensioning and they stayed at work during the follow-up time) and $b$ (individuals returned to work during the second year and stayed at work after returning to it). The partial RTW group was formed by clusters $c-e$. In cluster $c$ people returned to work after pensioning but they had just a few working days during the follow-up time. People in cluster $\mathrm{d}$ had working days during the first year and people in cluster e during the second year after pensioning, but they had only very few or no working days after that. In other words, people in the partial RTW group returned to work but did not stay there and they had just a few working days during the follow-up time. In the cluster $f$ individuals had none or only a few days at work; hence, they formed the no RTW group.
The second step in the analysis process detected the associations between the personal, socio-economic and health care-related variables in order to describe and to examine differences between RTW, partial RTW and the control group (people with no RTW) and to assess potential differences in these factors between groups separated by gender. The associations were analysed with the chi-squared test for the categorical variables. We also examined people's situations exactly 1-3 years after pensioning.

The third step in the analysis process utilized multinomial logistic regression analysis. First, we analysed the association between each variable and partial RTW as well as RTW with a univariable model and utilized logistic regression analysis to compute the odds ratios (ORs) between the outcome and the independent variables. Further, we created an adjusted multivariable model in which several independent variables were added to the model simultaneously. To find the best model for the data, we entered into the model the variables with $p<0.05$ at least for one of the genders and evaluated the goodness of the models with the Nagelkereke Pseudo- $R^{2}$ and the deviance tests. Statistical analysis was performed using SPSS software (version 25) and R-software (R Core Team R, 2019) with cluster (Maechler et al., 2019) package.

\section{Results}

Figure 1A illustrates six clusters showing the paths by which the individuals returned to work. Based on this, we assigned the individuals into three groups: RTW, partial RTW and no RTW (despite not permanently retired) (Fig. 1B). We could also identify groups of people who returned to work (RTW group) at different rates (clusters $a$ and $b$ in Fig. 1A). The partial RTW group was formed by people who had working days after one year (cluster d) or after 2 years of pensioning (cluster e), but no further working days after 3 years, and people who had returned to work after 3 years of pensioning but had just a few working days (cluster c). The control group (no RTW) consisted of people granted a temporary DB by using the same inclusion criteria but who had no or just a few working days (cluster $\mathrm{f}$ ) during the follow-up time.

Description of the study population. Table 1 shows the distribution of the factors separated by subjects with RTW, partial RTW and no RTW, with men and women calculated separately (men: $n=3613$; women: $n=5002$ ). The mean age of the men was 33 years (MD 31, SD 10) and of the women 35 years (MD 35, SD 11). Men were more often single, had only basic education and were manual workers 55\%, 40\%, $18 \%$; respectively, whereas, among women, the figures were $37 \%, 30 \%, 15 \%$, respectively.

There were differences in SES especially between people who returned to work and people who had no working days. For example, $21 \%$ of men and $44 \%$ of women who returned to work were lower-grade employees. By contrast, this was the case in $9 \%$ of men and $13 \%$ of women who had not returned to work.

The most common psychiatric diagnoses for temporary DP were affective disorders (F3*): $71 \%$ of women and $54 \%$ of men, followed by psychotic disorders (F2*): $15 \%$ of women and $30 \%$ of men. Furthermore, RTW was more common among subjects with affective disorders (women: $82 \%$; men: $71 \%$ ) compared to those with psychotic disorders (women: $9 \%$ and men: 19\%). The study population received vocational rehabilitation (women: $57 \%$ and men: $39 \%$ ) more often than rehabilitative psychotherapy (women: $29 \%$; men: 14\%). All differences were statistically highly significant $(p<0.001)$. 

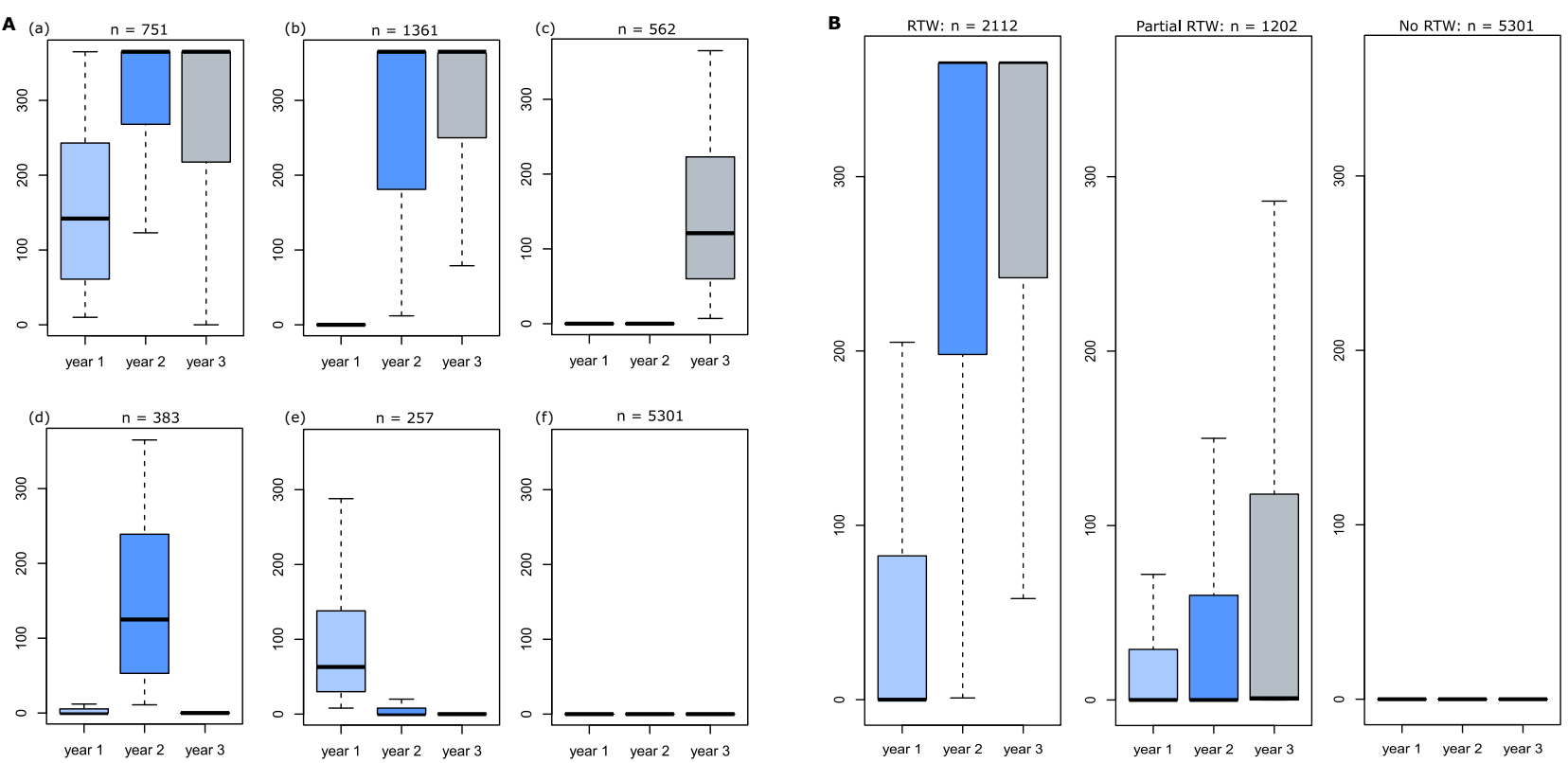

Fig. 1 The patterns of returning to work obtained by clustering analysis. The numbers of days at work of the people in clusters a- $f(\mathbf{A})$, and groups $1-3$ (B) during the 3 years follow-up. Clusters a and b are within the RTW group, whereas clusters c-e are within the partial RTW group. The cluster f had none or only few days at work, and thusthey form the no RTW group.

The three years follow-up. At the time point of 3 years from the initial temporary pensioning, the majority of the study population (69\% of men; $n=2495 ; 64 \%$ of women; $n=3179)$ had a temporary or a permanent psychiatric DB. In addition, $12 \%$ of men and $11 \%$ of women were unemployed, whereas $11 \%$ of men and $16 \%$ of women were at work, as can be seen in Fig. 2. However, both the number of people who returned to work and the number of days worked increased during the follow-up period (data not shown).

Return to work. To the results of unadjusted (Table seen in the Supplementary material) and adjusted multinomial logistic regression modelling, are seen in Table 2 and Fig. 3. The adjusted models included the variables statistically significant at least for one of the genders. Further, we evaluated the models with the Nagelkerke pseudo- $R^{2}$ resulting 0.256 for women and 0.226 for men. The results showed that being an upper-grade, a lower-grade or a manual worker remarkably promoted RTW for women, but also for men. In the adjusted model association was attenuated, but still clear. High education for women and tertiary education for men were the other significant factors promoting RTW. These associations weakened in the adjusted model. In addition, age was a significant factor for RTW, especially for men. The highest probability for RTW was in men aged 45-49 years and women aged over 55 years. Both male and female manual workers had an increased probability of partial RTW. Differences appear between the partial RTW and RTW groups among occupational status for men and women.

Furthermore, psychotherapy and rehabilitation increased the probability of RTW for men and women, but the association weakened for all in the adjusted model. Moreover, in an additional analysis we studied the combined effect of the rehabilitation and psychotherapy and found that those people who obtained both psychotherapy and rehabilitation had a higher probability of RTW (men: OR 2.15, 95\% CI 1.56-2.97; women: OR $2.2295 \%$ CI $1.51-1.99, p<0.001)$ than people obtaining only one or the other (men: OR $1.3695 \% \mathrm{CI}$ 1.14-1.63.; women: OR 1.73 95\% CI 1.51-2.00. $p<0.001)$.

\section{Discussion}

We aimed at examining personal, socio-economic, and healthcare-related factors associated with returning to work after temporary disability pensioning. In this study, women $(n=1468 ; 29.3 \%)$ returned to work more frequently than men $(n=544 ; 17.8 \%)$ and almost two-thirds of retirees $(65 \%$ of men and $62 \%$ of women) remained on DP during the 3 years follow-up period. Hence, RTW after long-term absence from work was generally not very common, but there were differences in the personal and SES factors of people who returned to work compared to those who had no working days after DP. In particular, being a lower-grade employee or having higher education seemed to promote RTW for women, as did being a manual worker or having tertiary education for men.

These findings are in line with those of several earlier Finnish studies of RTW after long term absence from work (Laaksonen and Gould, 2015; Mattila-Holappa et al., 2016; Pirkola et al., 2019). People with higher or tertiary education may have more opportunities to obtain employment and they may have jobs which are easier to modify (Johansson et al., 2006). On the other hand, the highly educated might have jobs with more complicated demands to which may be difficult to return; hence, RTW for the highly educated might take longer, as Nieuwenhuijsen et al. (2006) suggested. Furthermore, based on our data, the RTW rate was low for those who were unemployed before being granted temporary DP. This may relate to both lack of workplaces for them to return to, and on the other hand, the generally deteriorating effects of prolonged unemployment. Based on an earlier study, prolonged unemployment seemed to predict a low RTW rate after long-term absence (Pirkola et al., 2019).

In contrast to earlier findings (Hardeveld et al., 2010; Joensuu et al., 2018; Laaksonen and Gould, 2015), in our study, RTW after long-term absence from work was more common in the middle age groups (over 45 years) than in the youngest age group (18-25 years). An explanation for this might be that younger retirees had more often been granted DP for psychosis or other more severe mental disturbances, which had a poorer RTW rate. In addition, younger people 


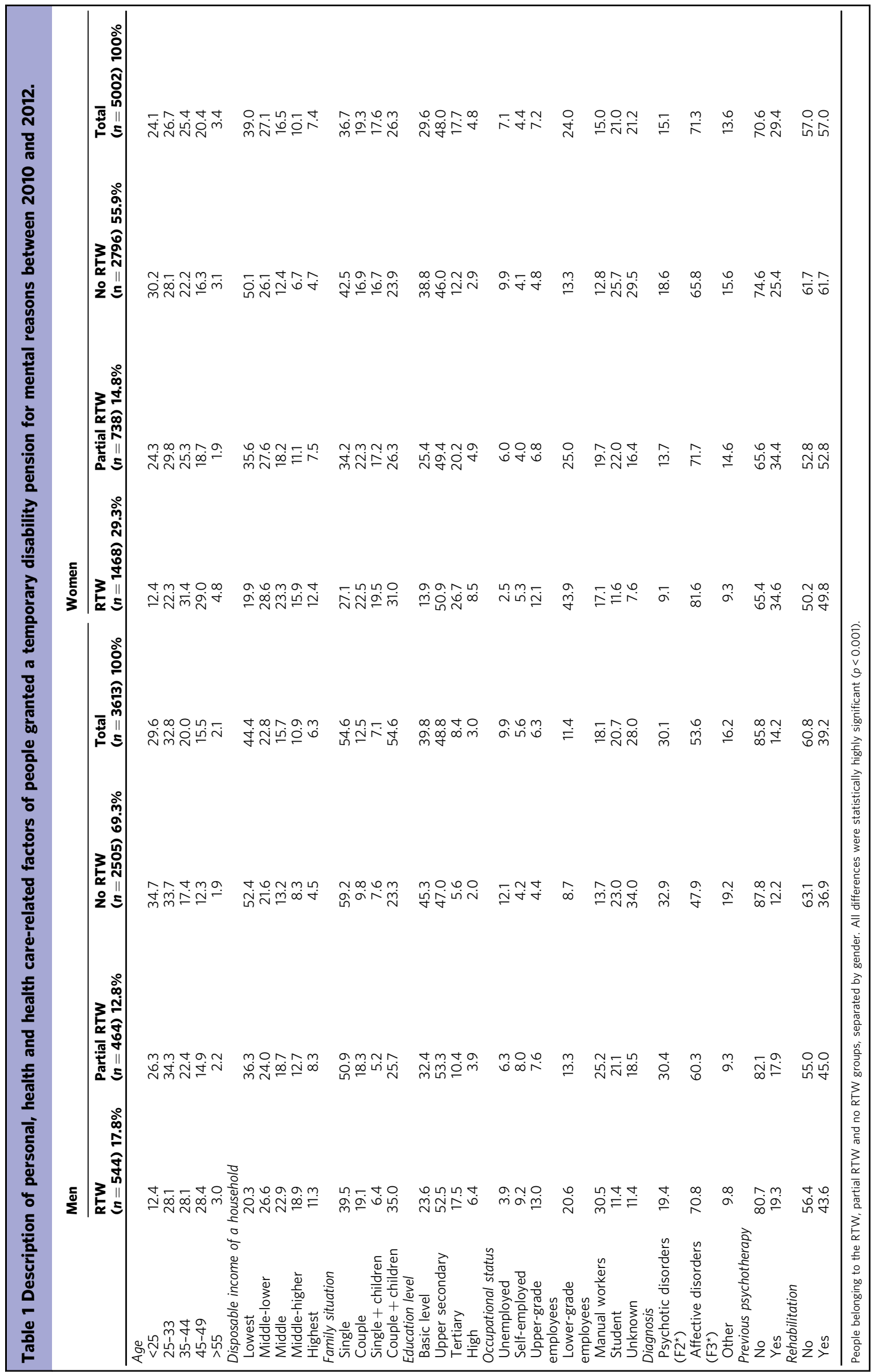




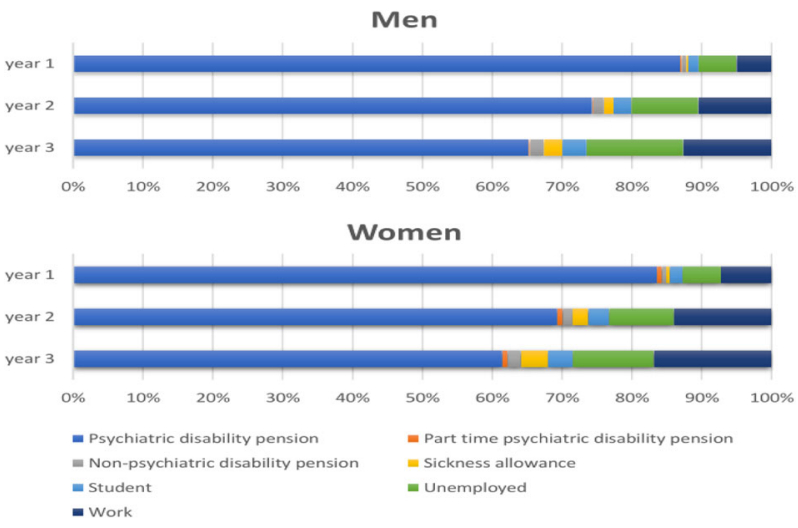

Fig. 2 Situation of people being granted a temporary disability pension between 2010 and 2012 for mental disorders after 1-3 years of pensioning, for men $(n=3613)$ and women $(n=5002)$. This figure is covered by the CC BY-NC-ND License.

may face stricter criteria than older people for being granted DP, which is in any case the last option. Furthermore, older people may more often have a workplace to return to and a better educational level than people in the youngest age group.

As for the characteristics of the temporarily retired population, we found differences in SES between men and women granted temporary DP: men were more often unemployed, had only basic education and were retired on the basis of psychotic disorders. By contrast, women were more often lower-grade employees, had a tertiary or higher level of education and were granted DP for affective disorders, and they received psychotherapy more frequently than men. These differences may be related to health characteristics, healthrelated behaviours, gender roles and differences in severity of illness, but also to different roles in occupational life. These findings are also in accordance with those of previous studies, which have suggested gender differences in the presentation and prevalence of mental disorders (Hayashi et al., 2016; Murphy et al., 2019), as well as studies which demonstrated that men had a lower RTW rate than women, regardless of the duration of absence from work (Blank et al., 2008; Cornelius et al., 2011; Laaksonen and Gould, 2015; Lagerveld et al., 2010; Mattila-Holappa et al., 2016). Because of gender differences in retirees' SES as well as work disability and RTW processes, it would be essential that programmes promoting RTW take into account these differences.

Another important finding was that previous rehabilitation and psychotherapy seemed to increase the probability of RTW. This is consistent with the data obtained in two Finnish studies (Laaksonen and Gould, 2015; Mattila-Holappa et al., 2016), but contrary to some other studies which have found no clear correlation between, for example, counselling, exercise, medical rehabilitation, or return-to-work programmes and RTW (Kuoppala and Lamminpää, 2008). A possible explanation for this contradiction might be that in Finland psychotherapy is usually received before obtaining DP, at an early stage. It is conceivable that rehabilitation and psychotherapies may promote people's work ability at an early stage of illness rather than at a later stage (Kuoppala and Lamminpää, 2008), when demands for rehabilitation are likely to increase because of factors such as marginalization and social inclusion. It must be also considered that the selection of the participants into psychotherapy and rehabilitation is very likely in this population results. Firstly, rehabilitees are selected for occupational rehabilitation by the experts of the insurance companies. Secondly, men who are unemployed have a lower education or low SES, are also less likely to have received psychotherapy and treatment (Virtanen et al., 2011). Accordingly, higher education might be related to higher prevalence of psychotherapy. However, in our study, even in the adjusted regression analysis model in which most of these variables were taken into account, the association between psychotherapy, rehabilitation and RTW remained. This suggests that selection according to these factors alone does not explain the association. Based on our study, psychotherapy and rehabilitation may promote RTW, when targeted properly. This implies that developing rehabilitation services may support RTW among those with impaired work ability.

Based on our results, most of the study population either returned to work partially or had no working days. People with partial RTW frequently had a peak of working days after pensioning, or they returned to work at a slow rate or to parttime work, but the majority of them were on DP or unemployed at the end of follow-up time. This may be connected to the typical periods of remission and recurrence of mental disorders (Hardeveld et al., 2010) or to conditions in working life. Part-time occupational settings may not have been optimal to them, or optimal or established in general either. On the other hand, especially after a long-term absence from work, it may be difficult to continue at a previous job or to get work. The paths of partially recovering to occupational functioning should perhaps be better planned and supported. It may also be important to establish procedures to support retirees who have returned to work to continue working, for example by using work modifications or work-oriented interventions as well as changes in the way of working and the conditions at work. Obviously, the workplace should also be a part of the rehabilitation.

Furthermore, almost two-thirds of the study population remained on a DP after being granted a temporary one and for example, (unemployed) young people with basic education and psychotic disorders have a high risk of dropping out of the labour market or not even entering it. Hence, it seems that we need more efficient ways to promote employment and RTW for people granted temporary DP, as well as more efficient prevention methods to exhibit prolonged work disability. There may also be a need for social support and supported employment. On the other hand, some temporary pensions could perhaps be permanent in the first place. Further research is needed to examine more closely the focusing of temporary DP. To whom and in which conditions is it meaningful? It may also be important to analyse and recognize aims, best timing and quality of interferences needed to promote peoples' work ability, not only in the social- and healthcare system and in service provision but also in working life and the education system.

Strengths and limitations. The main strengths of our study include the use of data based on reliable and good quality register sources of RTW and other variables. The study population included all new temporary disability pensioners granted due to mental disorder for 3 years in Finland; hence, we can systemically evaluate the RTW process in Finland. Another advantage is the wide range of socio-economic factors, with longitudinal data linked at the individual level, which could also be included as potential confounders. Furthermore, as the RTW is determined based on actual working days, not on the termination of the disability benefit, we can more reliably study how the subjects have returned to work. In addition, a major advantage is that in this study we demerged RTW and partial RTW. 
Table 2 A fully adjusted multinomial logistic model predicting total and partial return to work among a population of subjects temporarily retired due to psychiatric disorders.

\begin{tabular}{|c|c|c|c|c|c|c|c|c|}
\hline & \multicolumn{4}{|l|}{ Men } & \multicolumn{4}{|c|}{ Women } \\
\hline & OR & $95 \% \mathrm{Cl}$ & OR & $95 \% \mathrm{Cl}$ & OR & $95 \% \mathrm{Cl}$ & OR & $95 \% \mathrm{Cl}$ \\
\hline \multicolumn{9}{|l|}{ Family situation } \\
\hline Single & 1 & & 1 & & 1 & & & 1 \\
\hline Couple & 1.39 & $(1.03-1.87)^{\star}$ & 1.61 & $(1.17-2.22)^{\star}$ & 1.08 & $(0.87-1.34)$ & 1.22 & $(0.96-1.56)$ \\
\hline Single + children & 0.99 & $(0.67-1.48)$ & 0.71 & $(0.44-1.13)$ & 1.44 & $(1.16-1.8)^{\star \star}$ & 1.19 & $(0.92-1.54)$ \\
\hline \multicolumn{9}{|l|}{ Age } \\
\hline$<25$ & 1 & & 1 & & 1 & & 1 & \\
\hline $25-34$ & 1.96 & $(1.43-2.69)^{\star \star}$ & 1.26 & $(0.94-1.69)$ & 0.98 & $(0.77-1.25)$ & 1 & $(0.77-1.28)$ \\
\hline $45-44$ & 2.46 & $(1.73-3.5)^{\star \star}$ & 1.29 & $(0.9-1.84)$ & 1.42 & $(1.1-1.83)^{\star}$ & 0.97 & $(0.73-1.29)$ \\
\hline $45-49$ & 3.27 & $(2.27-4.72)^{\star \star}$ & 1.08 & $(0.72-1.62)$ & 1.51 & $(1.15-1.97)^{\star}$ & 0.92 & $(0.68-1.25)$ \\
\hline$>55$ & 2.13 & $(1.07-4.24)^{\star}$ & 1.01 & $(0.46-2.22)$ & 1.58 & $(1.03-2.41)^{\star}$ & 0.49 & $(0.26-0.94)^{\star}$ \\
\hline \multicolumn{9}{|c|}{ Disposable income of a household } \\
\hline Highest & 2.15 & $(1.41-3.29)^{\star \star}$ & 1.47 & $(0.91-2.36)$ & 2.19 & $(1.59-3.02)^{\star \star}$ & 1.39 & $(0.94-2.06)$ \\
\hline \multicolumn{9}{|l|}{ Education level } \\
\hline Basic & 1 & & 1 & & 1 & & 1 & \\
\hline Secondary & 1.5 & $(1.18-1.89)^{\star \star}$ & 1.29 & $(1.01-1.65)^{\star}$ & 2.11 & $(1.73-2.57)^{\star \star}$ & 1.43 & $(1.16-1.77)^{\star \star}$ \\
\hline Tertiary & 2.73 & $(1.91-3.9)^{\star \star}$ & 1.85 & $(1.22-2.81)^{\star}$ & 2.51 & $(1.95-3.24)^{\star \star}$ & 1.89 & $(1.42-2.53)^{\star \star}$ \\
\hline High & 2.17 & $(1.27-3.69)^{\star}$ & 1.53 & $(0.79-2.96)$ & 4.94 & $(3.36-7.27)^{\star \star}$ & 2.48 & $(1.54-3.99)^{\star \star}$ \\
\hline \multicolumn{9}{|l|}{ Occupational situation } \\
\hline Unemployed & 1 & & 1 & & 1 & & 1 & \\
\hline Self-employed & 4.18 & $(2.4-7.29)^{\star \star}$ & 3.58 & $(2.01-6.36)^{\star \star}$ & 3.24 & $(2.03-5.19)^{\star \star}$ & 1.38 & $(0.81-2.35)$ \\
\hline Upper-grade employees & 4.28 & $(2.44-7.51)^{\star \star}$ & 2.31 & $(1.24-4.31)^{\star}$ & 4.28 & $(2.74-6.67)^{\star \star}$ & 1.53 & $(0.93-2.51)$ \\
\hline Lower-grade employees & 5.05 & $(3.07-8.3)^{\star \star}$ & 2.73 & $(1.63-4.56)^{\star \star}$ & 7.85 & $(5.35-11.51)^{\star \star}$ & 2.43 & $(1.65-3.57)^{\star \star}$ \\
\hline Manual workers & 5.47 & $(3.4-8.78)^{\star \star}$ & 3.51 & $(2.19-5.63)^{\star \star}$ & 4.54 & $(3.06-6.73)^{\star \star}$ & 2.44 & $(1.66-3.59)^{\star \star}$ \\
\hline Student & 2.25 & $(1.35-3.74)^{\star}$ & 1.98 & $(1.23-3.19)^{\star}$ & 2.04 & $(1.37-3.05)^{\star \star}$ & 1.37 & $(0.94-2.01)$ \\
\hline \multicolumn{9}{|l|}{ Rehabilitation } \\
\hline No & 1 & & 1 & & 1 & & 1 & \\
\hline \multirow[t]{2}{*}{ Yes } & 1.23 & $(1.01-1.51)^{\star}$ & 1.44 & $(1.16-1.78)^{\star \star}$ & 1.3 & $(1.12-1.51)^{\star \star}$ & 1.29 & $(1.09-1.53)^{\star}$ \\
\hline & \multicolumn{4}{|c|}{ Nagelkerke Pseudo $R^{2}=0.226$} & \multicolumn{4}{|c|}{ Nagelkerke Pseudo $R^{2}=0.256$} \\
\hline
\end{tabular}

On the other hand, a limitation of the study is the rather short 3-year follow-up period from the beginning of DP. In addition, rehabilitative activity consists of a considerable variety of forms of interventions, although in this study we had to use a simplified variable, indicating whether subjects received rehabilitation or not. Thus, it does not provide information of the duration or volume of rehabilitation received.

The discrepancies of work disability benefits and systems, as well as terminologies and eligibilities across countries, restrain the generalizability and external validity of the results (Kaltenbrunner Bernitz et al., 2013; Polvinen et al., 2018; Spasova et al., 2016), although the Finnish system corresponds with agreements in several countries (OECD, 2010). Despite these limitations, the study adds to our understanding of RTW after long term absence from work because of mental disorders.

\section{Conclusion}

Our study illustrated the divergencies between genders and SES among people who had lost their work ability for a long time due to mental disorders. There are differences between men and women in psychiatric disability pensioning in their backgrounds and paths to return to work; hence, it would be important that programmes promoting RTW consider gender differences in mental disorders, work disability and RTW processes. Our analysis of personal and SES factors show that it is possible to recognize traits which may predict successful RTW. With the aid of rehabilitation and psychotherapy, people with good education and occupational status may have a higher probability of RTW. Further research is needed to develop procedures to enhance RTW. Our study included a register-based dataset, but along with that there is a definite need for reliable real-time indicators to estimate personal, economic, social, working life, educational and occupational issues. 

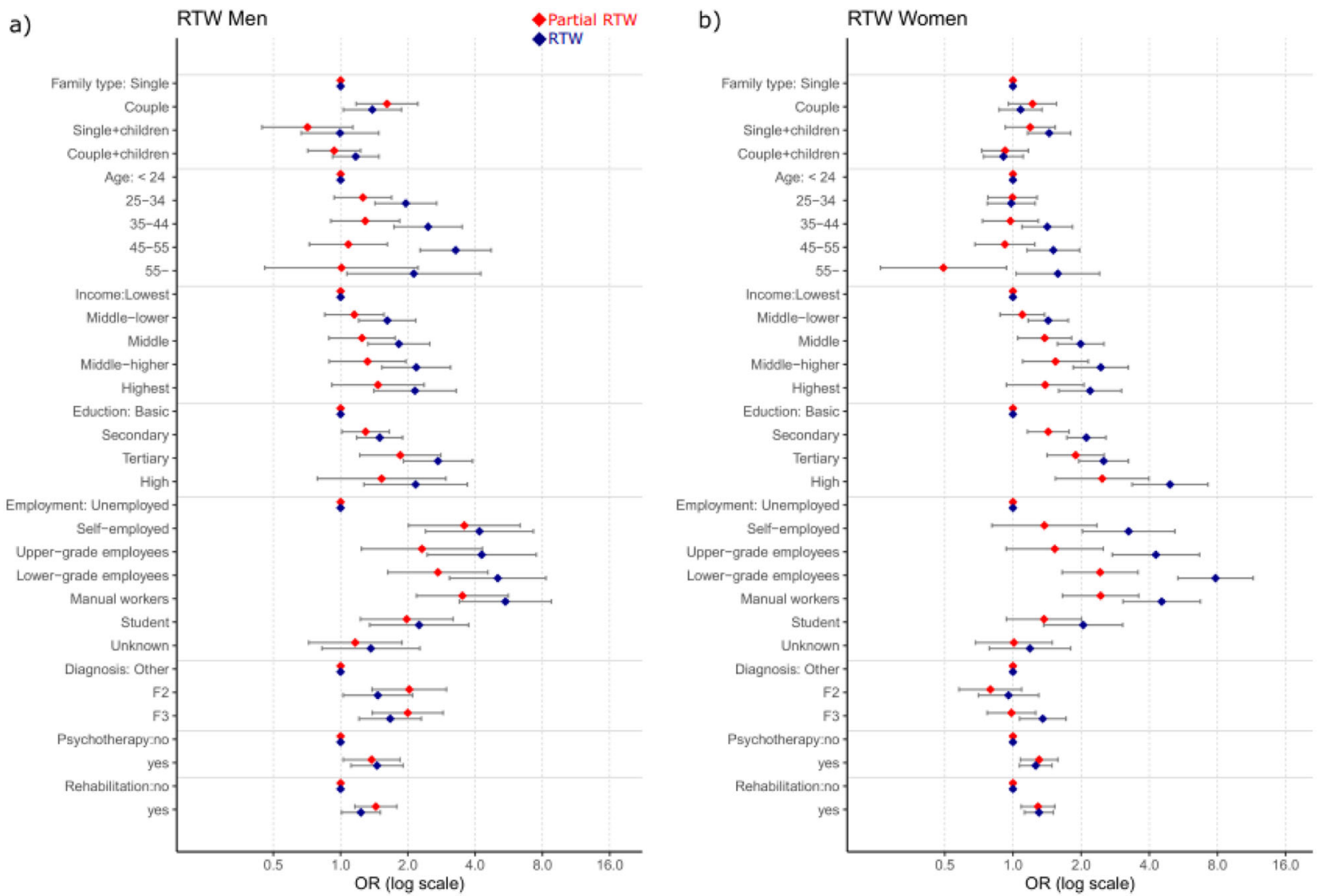

Fig. 3 Adjusted odds ratios of associations between personal, socio-economic, health and health care-related factors between people with partial RTW (red) and RTW (blue) after temporary disability pension, shown for men and women separately. This figure is covered by the CC BY-NC-ND License.

\section{Data availability}

Data are available for use from Statistics Finland through licensing and are regulated by the GDPR and the Finnish Data Protection and Statistics Acts. All analyses are available by the authors.

Received: 18 March 2021; Accepted: 15 October 2021; Published online: 10 November 2021

\section{References}

Blank L, Peters J, Pickvance S, Wilford J, MacDonald E (2008) A systematic review of the factors which predict return to work for people suffering episodes of poor mental health. J Occup Rehabil 18:27-34

Cornelius LR, van der Klink JJL, de Boer MR, Brouwer S, Groothoff JW (2016) High prevalence of early onset mental disorders among long-term disability claimants. Disabil Rehabil 38:520-527. https://doi.org/10.3109/09638288.2015.1046566

Cornelius LR, van der Klink JJL, Groothoff JW, Brouwer S (2011) Prognostic factors of long term disability due to mental disorders: a systematic review. J Occup Rehabil 21:259-274. https://doi.org/10.1007/s10926-010-9261-5

de Vries H, Fishta A, Weikert B, Rodriguez Sanchez A, Wegewitz U (2018) Determinants of sickness absence and return to work among employees with common mental disorders: a scoping review. J Occup Rehabil. 28:393-417. https://doi.org/10.1007/s10926-017-9730-1

Drake RE, Frey W, Bond GR, Goldman HH, Salkever D, Miller A, Moore TA, Riley J, Karakus M, Milfort R (2013) Assisting Social Security Disability Insurance beneficiaries with schizophrenia, bipolar disorder, or major depression in returning to work. Am J Psychiatry 170:1433-1441. https://doi.org/10.1176/ appi.ajp.2013.13020214

Ervasti J, Joensuu M, Pentti J, Oksanen T, Ahola K, Vahtera J, Kivimäki M, Virtanen M (2017) Prognostic factors for return to work after depression-related work disability: a systematic review and meta-analysis. J Psychiatr Res 95:28-36. https://doi.org/10.1016/j.jpsychires.2017.07.024

Ervasti J, Vahtera J, Pentti J, Oksanen T, Ahola K, Kivimäki M, Virtanen M (2013) Depression-related work disability: socioeconomic inequalities in onset, duration and recurrence. PLoS ONE 8:e79855. https://doi.org/10.1371/ journal.pone. 0079855

Hardeveld F, Spijker J, De Graaf R, Nolen WA, Beekman ATF (2010) Prevalence and predictors of recurrence of major depressive disorder in the adult population. Acta Psychiatr Scand 122:184-191. https://doi.org/10.1111/ j.1600-0447.2009.01519.x

Hayashi K, Taira Y, Maeda T, Matsuda Y, Kato Y, Hashi K, Kuroki N, Katsuragawa S (2016) What inhibits working women with mental disorders from returning to their workplace?-A study of systematic re-employment support in a medical institution. Biopsychosoc Med 10:29. https://doi.org/10.1186/s13030-016-0080-6

Hees HL, Koeter MWJ, Schene AH (2012) Predictors of long-term return to work and symptom remission in sick-listed patients with major depression. J Clin Psychiatry 73:1048. https://doi.org/10.4088/JCP.12m07699

Huijs JJM, Koppes LLJ, Taris TW, Blonk RWB (2017) Work characteristics and return to work in long-term sick-listed employees with depressive symptoms. J Occup Rehabil 27:612-622. https://doi.org/10.1007/s10926-017-9696-Z

Joensuu M, Mattila-Holappa, P, Ahola, K, Kivimäki, M, Tuisku, K, Koskinen, A, Vahtera, J, Virtanen, M (2018) Predictors of employment in young adults with psychiatric work disability. Early Interv Psychiatry. https://doi.org/ 10.1111/eip. 12730

Johansson G, Lundberg O, Lundberg I (2006) Return to work and adjustment latitude among employees on long-term sickness absence. J Occup Rehabil 16:185-195. https://doi.org/10.1007/s10926-006-9020-9

Kaltenbrunner Bernitz B, Grees N, Jakobsson Randers M, Gerner U, Bergendorff S (2013) Young adults on disability benefits in 7 countries. Scand J Soc Med 41:3-26T

Karolaakso T, Autio R, Näppilä T, Leppänen H, Rissanen P, Tuomisto MT, Karvonen S, Pirkola S (2021) Contextual and mental health service factors in mental disorder-based disability pensioning in Finland-a regional comparison. BMC Health Serv Res 21:1081. https://doi.org/10.1186/s12913-02107099-4 
Karolaakso T, Autio R, Näppilä T, Nurmela K, Pirkola S (2020) Socioeconomic factors in disability retirement due to mental disorders in Finland. Eur J Public Health 30:1218-1224. https://doi.org/10.1093/eurpub/ckaa132

Kaufman L, Rousseeuw PJ (1990) Finding Groups in Data: An Introduction to Cluster Analysis. John Wiley \& Sons, Ltd. 126-163

Kuoppala J, Lamminpää A (2008) Rehabilitation and work ability: a systematic literature review. J Rehabil Med 40:796-804. https://doi.org/10.2340/16501977-0270

Laaksonen M, Gould R (2015) Return to work after temporary disability pension in Finland. J Occup Rehabil 25:471-480. https://doi.org/10.1007/s10926-014-9554-1

Lagerveld SE, Bültmann U, Franche RL, Van Dijk F, Vlasveld MC, Van der FeltzCornelis CM, Bruinvels DJ, Huijs J, Blonk R, Van Der Klink J (2010) Factors associated with work participation and work functioning in depressed workers: a systematic review. J Occup Rehabil 20:275-292

Maechler M, Rousseeuw P, Struyf A, Hubert M, Hornik K (2019) Cluster analysis basics and extensions. R package version 2.1.0. https://cran.r-project.org/web/ packages/cluster/index.html

Mattila-Holappa P, Ervasti J, Joensuu M, Ahola K, Pentti J, Oksanen T, Vahtera J, Kivimäki M, Virtanen M (2017) Do predictors of return to work and recurrence of work disability due to mental disorders vary by age? A cohort study. Scand J Public Health 45:178-184

Mattila-Holappa P, Joensuu M, Ahola K, Vahtera J, Virtanen M (2016) Attachment to employment and education before work disability pension due to a mental disorder among young adults. BMC Psychiatry 16:143. https://doi.org/ 10.1186/s12888-016-0854-1

Murphy J, Viding E, Bird G (2019) Does atypical interoception following physical change contribute to sex differences in mental illness? Psychol Rev. https:// doi.org/10.1037/rev0000158

Nieuwenhuijsen K, Verbeek, Jos HAM, de Boer, Angela GEM, Blonk RWB, van Dijk FJH (2006) Predicting the duration of sickness absence for patients with common mental disorders in occupational health care. Scand J Work Environ Health 32:67-74

OECD (2013) Mental health and work: Sweden. OECD Publishing, Paris

OECD (2010) Sickness, disability and work: breaking the barriers: a synthesis of findings across OECD countries. OECD, Paris

Pensioners and Insured in Finland, 2012 (2013). Statistical Yearbook of the Social Insurance Institution. OfficialStatistics of Finland. The Social Insurance Institution. Helsinki, Finland

Pirkola S, Nevalainen J, Laaksonen M, Fröjd S, Nurmela K, Näppilä T, TuulioHenriksson A, Autio R, Blomgren J (2019) The importance of clinical and labour market histories in psychiatric disability retirement: analysis of the comprehensive Finnish national-level RETIRE data. Soc Psychiatry Psychiatr Epidemiol. https://doi.org/10.1007/s00127-019-01815-6

Pirkola S, Isometsä E, Suvisaari J, Aro H, Joukamaa M, Poikolainen K, Koskinen S, Aromaa A, Lönnqvist J (2005) DSM-IV mood-, anxiety- and alcohol use disorders and their comorbidity in the Finnish general population-results from the Health 2000 Study. Soc Psychiatry Psychiatr Epidemiol 40:1-10. https://doi.org/10.1007/s00127-005-0848-7

Polvinen A, Laaksonen M, Rantala J, Hietaniemi M, Kannisto J, Kuivalainen S (2018) Working while on a disability pension in Finland: association of diagnosis and financial factors to employment. Scand J Public Health 46:74-81. https://doi.org/10.1177/1403494817738460

R Core Team R (2019) A language and environment for statistical computing. R Foundation for Statistical Computing, Vienna, Austria

Spasova S, Bouget D, Vanhercke B (2016) Sick pay and sickness benefit schemes in the European Union,Background report for the Social Protection Committee's In-Depth Review on sickness benefits. European Commission
Statistics Finland (2019) Consumption unit (OECD). http://www.stat.fi/meta/kas/ kulutusyks en.html

Statistics Finland (1989) Classification of Socio-economic Groups 1989. https:// www.stat.fi/meta/luokitukset/sosioekon_asema/001-1989/index_en.html

Suijkerbuijk YB, Schaafsma, FG, Mechelen, JCV, Ojajärvi, A, Corbière, M, Anema JR (2017) Interventions for obtaining and maintaining employment in adults with severe mental illness, a network meta-analysis. Cochrane Database Syst Rev. 9(9):CD011867. https://doi.org/10.1002/ 14651858.CD011867.pub2

Virtanen M, Kawachi I, Oksanen T, Salo P, Tuisku K, Pulkki-Råback L, Pentti J, Elovainio M, Vahtera J, Kivimäki M (2011) Socio-economic differences in long-term psychiatric work disability: prospective cohort study of onset, recovery and recurrence. Occup Environ Med 68:791-798. https://doi.org/ 10.1136/oem.2010.061101

\section{Competing interests}

The authors declare no competing interests.

\section{Ethical approval}

The Ethical Committee of the National Institute of Welfare and Health gave its approval of the plan of the project.

\section{Informed consent}

The study is based on register data collected for administrative, development, and evaluation purposes on a regular basis. No patients were contacted individually, and none will be recognizable from the data.

\section{Additional information}

Supplementary information The online version contains supplementary material available at https://doi.org/10.1057/s41599-021-00952-1.

Correspondence and requests for materials should be addressed to Päivi Rissanen.

Reprints and permission information is available at http://www.nature.com/reprints

Publisher's note Springer Nature remains neutral with regard to jurisdictional claims in published maps and institutional affiliations.

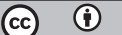

Open Access This article is licensed under a Creative Commons Attribution 4.0 International License, which permits use, sharing, adaptation, distribution and reproduction in any medium or format, as long as you give appropriate credit to the original author(s) and the source, provide a link to the Creative Commons license, and indicate if changes were made. The images or other third party material in this article are included in the article's Creative Commons license, unless indicated otherwise in a credit line to the material. If material is not included in the article's Creative Commons license and your intended use is not permitted by statutory regulation or exceeds the permitted use, you will need to obtain permission directly from the copyright holder. To view a copy of this license, visit http://creativecommons.org/ licenses/by/4.0/.

(c) The Author(s) 2021 